\title{
Microlitiasis testicular asociada a seminoma
}

\author{
Testicular microlithiasis associated with seminoma \\ Itzel Vargas Garduño, * Carolina González Vergara, * Elvira Olivia Bieletto Trejo, \\ Lizbett Hidalgo Pérez, ${ }^{\ddagger}$ Carlos Sánchez Moreno ${ }^{\S}$
}

La microlitiasis testicular se caracteriza por la presencia de calcificaciones intraluminales en los túbulos seminíferos. Se diagnostica ultrasonográficamente, lo cual se caracteriza por encontrar múltiples y dispersas imágenes hiperecogénicas, puntiformes y sin sombra acústica de entre 1 y $3 \mathrm{~mm}$ de diámetro. Debe haber por lo menos 5 microlitos en un testículo sano para realizar el diagnóstico.

Ésta es una entidad poco frecuente, pues se detecta en $0.6-9 \%$ de los ultrasonidos testiculares. Se clasifica de acuerdo con el número de microcalcificaciones testiculares como grado 1 cuando hay 5 a 10 microlitos, grado 2, 10 a 20 microlitos y grado 3 por la presencia de más de 20 microlitos. ${ }^{1}$
La microlitiasis testicular se ha asociado con otras patologías como varicocele, epididimitis, hidrocele y patologías de tipo cromosómicas, como son el síndrome de Klinefelter y el síndrome de Down. Las neoplasias testiculares son la asociación más importante, ya que se ha encontrado que, en pacientes portadores de éstas, la microlitiasis está presente en $10 \%$.

Se ha propuesto que su génesis podría estar ligada a isquemia, atrofia y degeneración de tejido testicular disgenético, que son las mismas causas implicadas en el desarrollo de neoplasias testiculares. La etiología se ha asociado también con la incapacidad de las células de Sertoli para fagocitar las células degeneradas en los túmulos

Figura 1:

A) Imagen ultrasonográfica panorámica de testículo izquierdo con neoplasia sólida

(seminoma clásico) en el polo inferior. B) Microlitiasis testicular grado 3 caracterizada por incontables imágenes hiperecoicas de distribución difusa. C) Acercamiento a la neoplasia testicular izquierda con saturación Doppler

aumentada. D) Testículo derecho que demuestra los microlitos y quistes simples en la cabeza del epidídimo.
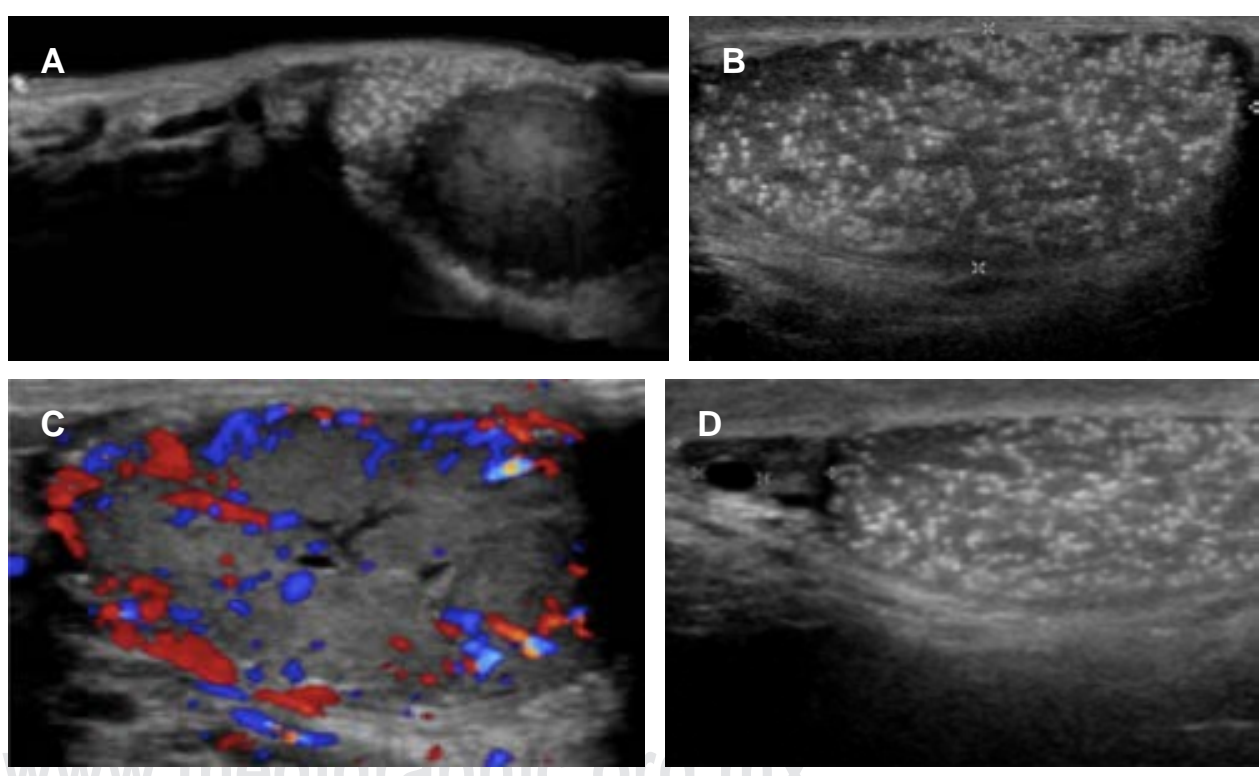

\footnotetext{
* Departamento de Radiología e Imagen.

₹ Departamento de Anatomía Patológica.

§ Urólogo.
}

Correspondencia: Itzel Vargas Garduño Correo electrónico: Itzi1521@hotmail.com

Aceptado: 18-12-2019. 
Figura 2:

Corte histológico de la neoplasia testicular izquierda con diagnóstico de seminoma.

A) Tinción H\&E 40X. Células grandes con población dismórfica de células seminomatosas con nucleolos prominentes entremezcladas y con células de bordes bien delimitados; citoplasma claro e infiltrado

linfocítico. B) Tinción H\&E 20X.

Láminas de células tumorales seminomatosas uniformes asociadas con microcalcificaciones. C) Tinción H\&E 20X.

Células tumorales seminomatosas claras divididas por lóbulos mal delimitados por tabiques finos y túbulos con hipoespermatogénesis. D) Tinción PAS 20X. Epitelio germinal bien conservado con calcificaciones intratubulares.
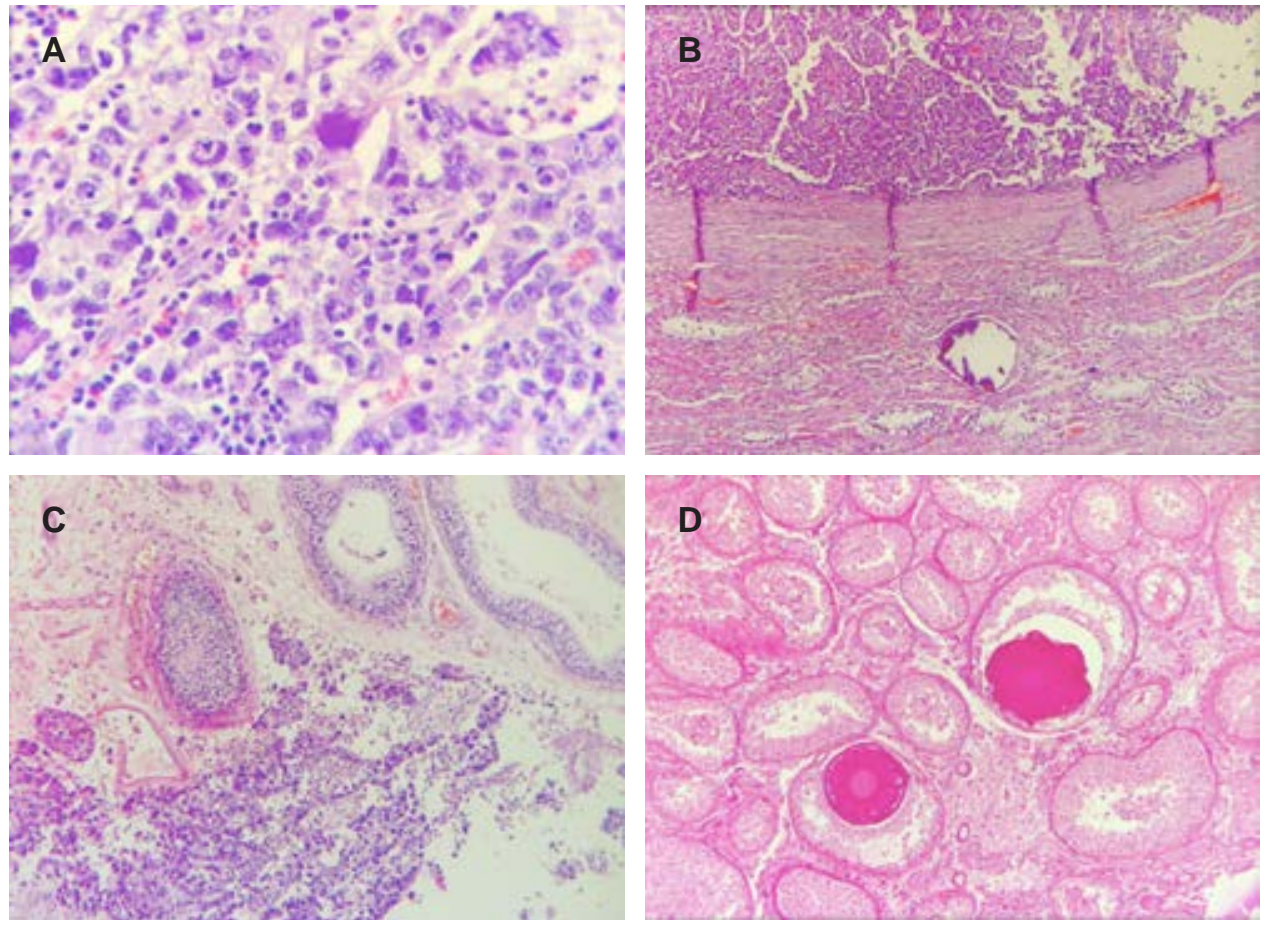

seminíferos, pues hay acumulación de restos celulares con la consiguiente calcificación. ${ }^{1}$

Los microlitos pueden estar agrupados o dispersos, y se ha definido que es de mayor importancia encontrarlos agrupados, ya que la agrupación pudiera denotar un área disgenética que diera desarrollo a un carcinoma in situ. ${ }^{2}$ Se ha encontrado infertilidad asociada hasta en $2.8 \%$ de los pacientes con microlitiasis testicular. ${ }^{3}$

Debido al incremento de padecer neoplasias asociadas, Holm y colaboradores proponen continuar con seguimiento ultrasonográfico al testículo contralateral posterior a una orquiectomía.

Los tumores testiculares que más se asocian a microlitiasis son: seminoma, tumor de células germinales y carcinoma embrionario. ${ }^{1,4}$

Una vez hecho el diagnóstico, se debe realizar autoexploración testicular mensual, ultrasonido testicular anual y marcadores tumorales. ${ }^{1,2}$

Se presenta el caso de un paciente masculino de 27 años de edad, sin antecedentes de importancia, con dolor en el testículo izquierdo e induración del mismo de un mes de evolución.

Al momento de la exploración física hay engrosamiento de la piel escrotal. El testículo izquierdo se palpa indurado, doloroso y con aumento de volumen; el epidídimo está engrosado y el testículo contralateral está sin alteraciones.

Se realiza espermatobioscopia con los siguientes hallazgos: semen blanco grisáceo, volumen $3.8 \mathrm{~mL}$, concentración de espermatozoides $12 / \mathrm{mL}$, conteo de es- permatozoides 45.6 millones, motilidad progresiva de $5 \%$, motilidad no progresiva de $12 \%$ y motilidad total de $17 \%$; espermatozoides inmóviles 83 y vitalidad $21 \%$.

Los marcadores tumorales fueron: alfafetoproteína (AFP) $3.01 \mathrm{IU} / \mathrm{mL}$, gonadotropina coriónica humana (HGC) fracción B $2.76 \mathrm{mUI} / \mathrm{mL}$.

El perfil hormonal fue: $\mathrm{LH} 2.82 \mathrm{UI} / \mathrm{mL}, \mathrm{FSH} 4.65 \mathrm{UI} / \mathrm{mL}$, estradiol $50.1 \mathrm{pg} / \mathrm{mL}$, progesterona $0.294 \mathrm{ng} / \mathrm{mL}$, prolactina $9.45 \mathrm{ng} / \mathrm{mL}$, testosterona $832 \mathrm{ng} / \mathrm{dL}$.

\section{CONCLUSIÓN}

La microlitiasis testicular es una entidad poco frecuente. Debido a su asociación con neoplasias, requiere seguimiento con el único método no invasivo que permite su diagnóstico: el ultrasonido.

\section{REFERENCIAS}

Ramos SJ, Valtorta I, Rojas L, Lazzarini H, Salas J, Trombini M et al. Microlitiasis testicular y cáncer de testículo. Rev Argde Urol. 2010; 75 (4): 231-234.

2. Richenberg J, Belfield J, Ramchandani P, Rocher L, Freeman S, Tsili A et al. Testicular microlithiasis imaging and follow-up: guidelines of the ESUR scrotal imaging subcommittee. Eur Radiol. 2015; 25 (2): 323-330.

3. Zastrow S, Hakenberg O, Wirth M. Significance of testicular microlithiasis. Urologia Internationalis. 2005; 75 (1): 3-7.

4. Hernández Tóriz N. Microlitiasis testicular en pacientes con carcinoma testicular. Colegio Mexicano de Urología. 2004; 19 (1): 27-31. 